\title{
SEGREGAÇÃO RESIDENCIAL E DISCRIMINAÇÃO NA ÁREA METROPOLITANA DE LISBOA: O OLHAR DAS CRIANÇAS
}

\author{
Maria João Leote de Carvalho *
}

RESUMO: Como representam as crianças os bairros onde vivem foi a questão orientadora a que a pesquisa apresentada neste artigo procurou responder, com base numa técnica visual (desenho) e tendo por contexto seis bairros de realojamento na área metropolitana de Lisboa, Portugal. $\mathrm{Na}$ análise das perceçóes de 312 crianças sobre os bairros, observa-se que a segregação residencial é representada como uma forma de violência: física, pelas limitaçóes que impóe; simbólica, pelos efeitos nas relações sociais. As lógicas de segregação territorial e as dinâmicas sócio espaciais estruturam as relaçóes entre pares e com adultos e a etnização dos laços e redes sociais das crianças, manifestada em várias formas de discriminação relativamente a outros grupos, é um fenômeno multidirecional.

Palavras-chave: Crianças. Políticas de Habitação Social. Segregação Residencial. Discriminação. Violência.

\section{RESIDENTIAL SEGREGATION AND ETHNIC DISCRIMINATION IN THE LISBON METROPOLITAN AREA: THROUGH CHILDREN'S EYES}

ABSTRACT: This article discusses the development of a mixed methods approach to the study of children's everyday mobility. The study presented here combined ethnographic fieldwork with GPS (Global Positioning System) technology and an interactive questionnaire that the children completed via mobile phone. This methodology permitted the researchers to generate a fuller understanding of children's everyday movements through the rich dataset documenting children's subjective experiences, systematic observations, mapping and survey data. We conclude that the success of mixed methods research requires close cooperation through interdisciplinary dialogue and mutual engagement in and coordination of activities and perspectives.

Keywords: City. Children. Social Housing Policies. Social Ecology. Ethnic Discrimination. Violence.

\footnotetext{
* Universidade de Nova Lisboa, Centro de Estudos em Sociologia, Lisboa, Portugal. E-mail de contato: mjleote@sapo.pt.
} 


\section{LA SEGREGATION RESIDENTIELLE ET LA DISCRIMINATION ETHNIQUE DANS LA REGION METROPOLITAINE DE LISBONNE: LE REGARD DES ENFANTS}

RÉSUMÉ: Cet article analyse la première phase d'une étude de cas qui examine la socialisation des enfants dans six quartiers de la région métropolitaine de Lisbonne. Dans la combinaison de méthodologies qualitatives, y compris, les techniques visuelles, la ségrégation résidentielle et la discrimination ethnique ont émergé comme axes (de)structurants dans la vie des enfants. L'ethnicisation des réseaux sociaux dans les quartiers, abordée ici selon les regards des enfants, sert à développer leurs compétences, à structurer leurs relations actuelles entre eux et avec les adultes. La ségrégation résidentielle est représentée comme une forme de violence: d'une part, physique, par les limitations qu'elle impose; de l'autre, symbolique, par les effets qu'elle apporte aux relations sociales.

Mots-clés: Enfants. Politiques de Logement Social. Ecologie Sociale. Discrimination Ethnique. Violence.

\section{Introdução}

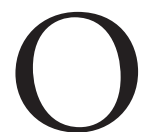

território onde as crianças residem e crescem assume um importante papel na maneira como se relacionam com os problemas sociais. Pobreza, exclusão social, violência, discriminação em função da origem étnica, cultural ou de gênero, acesso à educação e ao mercado de trabalho são aspetos que, desde cedo, as crianças percepcionam a partir do seu quadro de vida. (BENBENISTHY; ASTOR, 2005) Sabe-se como os territórios proporcionam aos indivíduos múltiplas formas de ocupação do espaço físico e potenciam a construção do espaço social, de referência das construçóes sociais, fundamental na construção identitária. (CHRISTENSEN; O'BRIEN, 2003; MOIGNARD, 2008) Habitar um território diz respeito ao espaço físico, próximo e afastado, e à forma social e pessoal de o apreciar, produzir e viver.

Em qualquer parte do mundo, a vida das crianças ocorre num território concreto que usam, apropriam, reconstroem e representam de modo diferenciado dos adultos. (CORSARO, 2005) Quer tenha havido ou não a possibilidade da família escolher a localização do alojamento, o bairro onde residem influencia as opções e oportunidades de socialização que as crianças têm ao dispor. (SEATON; TAYLOR, 2003)

Como as crianças representam o bairro onde vivem? Esta foi a questão orientadora a que a pesquisa apresentada neste artigo procurou responder tendo por contexto seis bairros de realojamento na área metropolitana de Lisboa, Portugal. Através da aplicação de uma técnica visual (desenho do bairro) traçou-se um 
quadro de análise das perceçôes das crianças sobre o local de residência. A opção pelo uso da expressão bairro de realojamento remete para uma política pública de habitação social que assentou em processos de relocalização de populaçóes que conduziram, ou podem ter mantido, a segregação residencial e concentração de desvantagens sociais em alguns territórios em vez da promoção de outras soluçóes. Se é certo que estes são espaços onde está identificada a existência de vários problemas sociais, também está provado que esses problemas não se encontram ou se produzem só no seu interior, nem podem ser analisados sem se ter em consideração o funcionamento de sistemas sociais (ensino, saúde, ação social, segurança e justiça), tanto a montante como a jusante. (MACHADO; SILVA, 2009) Pelo caráter exploratório da pesquisa, os resultados obtidos restringem-se à população e contexto à data estudados, não podendo ser generalizados a outros territórios.

\section{Viver a cidade}

A diversidade cultural e étnica é uma marca incontornável das sociedades urbanas num quadro de globalização. A exigência atual que se coloca a todos os indivíduos e grupos sociais é a da promoção de uma convivência comum, no respeito pela diferença que o outro representa em espaços onde todos se cruzam. Esta interação assume especial incidência nas cidades e metrópoles para onde tendem a confluir os mais variados fluxos migratórios. As pertenças de natureza diversa - culturais, étnicas, geográficas, religiosas, sociais e outras - definem uma identidade pessoal pelo que as questóes da multiculturalidade não podem ser fechadas somente numa ideia de coletivo, relativa a diferentes grupos, mas implicam cada indivíduo em si mesmo. (CASTRO et al., 2006)

Vivemos numa era de globalização em que a tradicional estratificação dos recursos pelo espaço marca a organizaçáo social. Apesar do progresso, nas sociedades ocidentais as desigualdades sociais têm vindo a crescer, talvez mesmo, a exacerbar-se. (SASSEN, 2001) Se por um lado a globalização tem potenciado uma ideia de desterritorialização da cidade, pela difusão de estilos de vida que não estão circunscritos aos seus limites territoriais, por outro, a divisão social do espaço urbano acarreta segregaçóes e discriminaçóes que se traduzem na desigualdade de oportunidades no acesso a recursos materiais e simbólicos e numa acentuada dificuldade de exercício ao nível da participação social que a todos afeta.

A reconfiguração das cidades para as funçóes que os novos espaços econômicos, de comunicaçóes e serviços qualificados exigem sustenta a perda de populaçóes do centro para as periferias, num processo de "nova urbanidade descentralizada”. (OLIVEIRA et al., 2004, p. 94) A espacialização da diferenciação social tende a revelar-se na emergência de áreas urbanas e suburbanas socialmente desfavorecidas, recorrentemente qualificadas como críticas, sensiveis ou problemáti- 
cas. (WACQUANT, 2007) A estes contextos, nichos de concentração de pobreza e de problemas sociais, segregados social e territorialmente, muitas vezes de forma compulsiva sobre aqueles que não dispóem de condições para aceder ao mercado privado de habitação, sobrepóem-se relaçóes de força e de poder entre os diferentes grupos sociais a partir das quais se constroem modos e estilos de vida.

A segregação residencial, enquanto uma das dimensóes espaciais da realidade social (MORENOFF; SAMPSON; RAUDENBUSH, 2001; WACQUANT, 2007), congrega três níveis de análise. O primeiro, objetivo, refere-se à concentração de certos grupos sociais em determinadas áreas geográficas, especialmente urbanas; o segundo destaca a tendência para homogeneidade social em alguns territórios; e o terceiro foca-se na perceção subjetiva formada pelos olhares individuais e coletivos sobre os dois primeiros níveis. A cidade é, assim, uma unidade social onde as relaçóes sociais se traduzem na sua morfologia, num determinado modo de territorialidade, isto é, de relação entre o espaço físico e a vida social. Neste âmbito, as distâncias espaciais traduzem também as distâncias sociais estabelecidas na interação entre indivíduos. (MACHADO; SILVA, 2009)

Os grupos sociais são objeto de análise em função da sua posição espacial e na relação com a composição social da cidade ou metrópole, situaçóes que influem nos processos de socialização na infância. Os espaços locais são fundamentais para a realização individual e coletiva e, em zonas marcadas por segregação residencial, os moradores podem estar mais dependentes do ambiente físico e social local para o estabelecimento de redes de suporte do que outros que vivem em locais onde esse suporte não passa só pelo espaço local. Deste modo, a organização social das zonas segregadas, que devia mediar os efeitos da desvantagem ecológica na socialização das crianças, pode constituir, de modo inverso, um elemento catalisador de desvantagens sociais que se vão sedimentando num aprofundamento das diferenças e desigualdades sociais. Na comparação entre crianças de diferentes zonas residenciais, vários autores evidenciam que são as que vivem em contexto de segregação residencial que tendem a apresentar uma maior probabilidade de serem vítimas de discriminação e violência pelas vulnerabilidades e maiores riscos que o isolamento e concentração territorial de problemas sociais acarreta. (BENBENISTHY; ASTOR, 2005) O peso do estigma dos nomes dessas zonas, nos mais diversos países, traduz-se frequentemente num alarme e rejeição social que, objetivamente, limita o acesso das crianças e famílias a estruturas de oportunidades diferenciadas. (WACQUANT, 2007)

Nesses territórios, as culturas de pares adquirem um papel preponderante e novas tensões emergem, a diferentes níveis, na socialização das crianças. Em muitos casos, a natureza e densidade dos laços sociais, associada a uma baixa eficácia coletiva, faz emergir uma diversidade de manifestações e ações paralelas que tendem a prevalecer sobre a cultura normativa vigente (MORENOFF; SAMPSON; RAUDENBUSH, 2001) e a socialização numa cultura de rua marca 
decisivamente os modos de vida e perceções das crianças residentes. (MOIGNARD, 2008)

É inquestionável que, à luz das transformaçóes sociais, o discurso sobre a criança e a cidade tem vindo a crescer em torno da insegurança e discriminação. São duas características das grandes metrópoles onde riqueza e exclusão social se encontram lado a lado. Decorrem de processos de forte diferenciação espacial, social e cultural que se associam a situaçóes de risco e constituem fatores que sustentam a ansiedade parental e familiar em relação à sua própria segurança e à das suas crianças. Na base encontra-se um quadro social complexo onde imagens e representaçôes sobre o risco social e a infância se constroem em sobreposição. Da fragmentação social, tão característica da vida urbana, emerge a tendência para o enfoque territorial de certos problemas sociais na infância, de vulnerabilidades e discriminaçóes que, independentemente da proximidade ou desfasamento à realidade, serve para a edificação de modos de identificação a lugares e a práticas e discursos distintos sobre os mesmos.

\section{Metodologia}

A pesquisa apresentada fez parte de um projeto de investigação de doutorado em sociologia centrado na relação entre infância, território e delinquência. Entre 2005 e 2009 foi realizado um estudo de caso com o objetivo de analisar os processos de socialização na infância em seis bairros de realojamento na área metropolitana de Lisboa e o envolvimento de crianças residentes em delinquência. A primeira etapa da investigação correspondeu à pesquisa discutida neste artigo em que se procurou conhecer como as crianças representavam os bairros onde viviam. ${ }^{1}$ Para este fim, optou-se por uma técnica visual (desenho do bairro) e a informação recolhida permitiu traçar um quadro de análise das perceçóes das crianças, examinando o que percecionaram como negativo e positivo no contexto de residência. Este quadro adquiriu especial relevância na continuidade dos trabalhos ao permitir enquadrar os fenômenos de delinquência, analisados em etapa posterior do projeto de doutorado, a partir do olhar das crianças.

\section{Contexto}

Os seis bairros de realojamento localizam-se num dos municípios mais ricos do país (Oeiras), o primeiro a ter erradicado as barracas no seu território, em 2003, após forte investimento numa política de habitação social. Construídos entre 1980 e 2000, os seis bairros abrangiam mais de $40 \%$ do total da população municipal em arrendamento social (1.700 habitaçóes). Cinco bairros são 
contíguos e o sexto localiza-se a cerca de um quilômetro pelo que, no conjunto, constituem uma vasta mancha territorial, separada de outras zonas residenciais socialmente diferenciadas por terrenos baldios, autoestradas e alguns armazéns. Os serviços existentes servem os seis bairros, independentemente da sua localização, e muitas famílias estão dispersas em mais do que um dos bairros, o que promove uma elevada mobilidade e circulação dos residentes.

Segundo os dados oficiais, os traços de caraterização sócio demográfica dos residentes dos seis bairros era comum. No total, 5.000 residentes dos quais $32,2 \%$ entre $0-18$ anos e $41,5 \%$ abaixo dos 30 anos. Os adultos possuíam baixas qualificaçôes escolares (17,6\% analfabetos; $38,0 \%$ com o $1^{\circ}$ ciclo; $17,1 \%$ com o $2^{\circ}$ ciclo) e só um terço tinha atividade profissional $(33,8 \%)$. Uma população com proveniências heterogêneas que abrangia grupos étnicos diferenciados, sobretudo de origem africana, a par de uma representatividade significativa de famílias ciganas, que integravam indivíduos que aderiram à cultura cigana por via do casamento, o que constitui um traço diferenciado de outros núcleos da população cigana no país. Apesar de 70,1\% do total dos residentes dos seis bairros ter nascido em Portugal, só $41 \%$ tinha nacionalidade portuguesa e $44,5 \%$ nacionalidade cabo-verdiana.

\section{Participantes}

Para garantir a uniformidade de procedimentos junto das crianças dos seis bairros, os desenhos foram recolhidos nas duas escolas públicas ( $1^{\circ}$ ciclo do ensino básico) que atendem esta população ${ }^{2}$, integradas no programa Territórios Educativos de Intervenção Prioritária. Criado em 1996 pelo Estado português como medida de discriminaçáo positiva de promoçáo do sucesso educativo, este programa foi inspirado na política de zones d'éducation prioritaires, na França, e em intervençōes norte-americanas e britânicas de educaçáo compensatória desenvolvidas em programas de combate à pobreza. Em 2006, o programa foi reformulado e selecionados os 35 agrupamentos de escolas localizados nos contextos socialmente mais desfavorecidos e problemáticos das áreas metropolitanas de Lisboa e do Porto. Com base num contrato-programa plurianual estabelecido com o Ministério da Educação, as escolas passaram a beneficiar de medidas excecionais para combater o insucesso, abandono escolar, insegurança e indisciplina, alicerçadas em evidências e no conhecimento que detêm sobre as realidades locais. A intervenção assenta num plano de melhoria de resultados, de financiamento e de recursos, num processo monitorizado por serviços do ministério e supervisores externos. ${ }^{3}$ 
A recolha da informação ocorreu durante três anos letivos consecutivos, abrangendo 70,8\% do total de alunos matriculados entre 2006 e 2008 . Na realização dos desenhos participaram 312 crianças, entre os seis e os 13 anos $(M=8.38)$, de ambos os gêneros, metade meninos $(n=156)$, metade meninas, residentes nos seis bairros. Para avaliar os efeitos da idade, foram agrupadas em dois grandes escalóes etários: 6-9 anos $(n=236,75,0 \%$, ) e 10-13 anos $(n=76,25,0 \%)$. A maioria era de origem africana $(n=196,62,8 \%)$, principalmente de ascendência cabo-verdiana, e $9,2 \%(\mathrm{n}=29)$ de origem cigana. Grande parte provinha de famílias desfavorecidas, com 86,7\% (n=271) a usufruir de Ação Social Escolar.

\section{Procedimentos e análise da informação}

Foi formalmente solicitada a autorização aos órgãos de gestão das escolas para o acesso à população estudantil e, na sequência de resposta positiva, foi entregue aos encarregados de educação um pedido de autorização para a participação das crianças na pesquisa. Idêntico procedimento de consentimento informado foi realizado com as crianças.

O tratamento da informação recolhida foi sustentado numa lógica analítica compreensiva centrada na voz das crianças (desenho e descrição). Ao tomar-se o desenho como ferramenta metodológica, mais do que focar a análise numa visão fechada sobre o produto final, que redundaria numa interpretação adultocêntrica, considerou-se ser fundamental ouvir as crianças sobre os processos de criação, as leituras que fazem, visando a apreensão dos significados atribuídos aos desenhos. Enquanto produto resultante de uma ação individual, num determinado espaço e tempo, o desenho articula simbolicamente os vários planos de existência da condição de vida da criança. $\mathrm{Na}$ sua interpretação há que atender a uma tripla dimensão: o desenho como produto único, singular, de uma criança específica; como artefacto social, que permite desocultar as regras e os valores dos quadros de vida de crianças pelo acesso às culturas da infância; e como objeto simbólico através do qual se dá expressão a um grupo geracional específico, o da infância. (SARMENTO, 2011)

Partiu-se para o terreno com a ideia que "o desenho das crianças é, afinal, o desenho de um mundo”. (SARMENTO, 2011, p. 56) Em pequeno grupo (3-4) em sala de aula ou polivalente, com base num enunciado simples ("és capaz de fazer um desenho sobre o teu bairro") solicitou-se a criação individual do desenho. À medida que foram sendo concluídos, ocorreram conversas informais individuais com a investigadora, visando a identificação dos conteúdos e significados que cada criança atribuiu ao que tinha desenhado. Nos casos em que o domínio da escrita era insuficiente, o registro da descriçáo ficou a cargo da investigadora, passando a escrito o que a criança dizia. 
Todos os desenhos foram digitalizados com a respetiva descrição, seguindo-se a organização em arquivos com base na idade ao momento da recolha. Mediante o preenchimento de grelhas de análise que contemplaram a conjugação de dois planos de análise - o da representação gráfica e o da descrição - numa só unidade, identificaram-se os padróes emergentes, de semelhanças e de diferenças, acompanhando-se este trabalho com um olhar sobre as notas de campo. Em função da pertinência do analisado, as dimensóes iniciais de análise foram desdobradas em categorias e subcategorias. Para testar efeitos de gênero e idade, foi realizada análise do qui quadrado. Por a lei portuguesa restringir a recolha e tratamento de dados pessoais referente a origem étnica, tanto ao Estado como a investigadores, não foi possível usar a etnia como variável na análise dos dados, nem mencioná-la nos desenhos e descriçóes individuais. ${ }^{4}$ Como se terá oportunidade de verificar na discussão dos resultados, este é um constrangimento que limita o conhecimento sobre a realidade social estudada nesta pesquisa.

\section{Os bairros pelo olhar das crianças}

$\mathrm{Na}$ análise dos desenhos dos bairros, os aspetos negativos apontados pelas crianças sobrepuseram-se aos positivos. Esta tendência adquiriu maior relevância quando focaram as pessoas $\left(X^{2}=125, p<.05\right)$ e os equipamentos públicos $\left(X^{2}=85, p<.05\right)$; num grau um pouco inferior, mas ainda expressivo, quando se reportaram ao espaço público $\left(X^{2}=31, p<.05\right)$ e comércio/serviços $\left(X^{2}=31, p<.05\right)$. Por outro lado, a habitação $\left(X^{2}=12, p<.05\right)$, as escolas $\left(X^{2}=18, p<.05\right)$ e a família $\left(X^{2}=8, p<.05\right)$ suscitaram valoraçóes mais positivas do que negativas. De registrar a ligeira diferença na representação de outras crianças, associada a uma certa conflitualidade. Em todas as categorias não foram registradas diferenças de gênero estatisticamente significativas.

A apreciação mais negativa, manifestada por quase metade $(47,1 \%)$ das 312 crianças, remete para o campo da interação social, as pessoas (adultos) com quem privavam ou conheciam. Independentemente da idade, gênero e bairro, esta valoração abordou desde as atitudes e comportamentos dos adultos, muitos entendidos como perturbadores e desordeiros, até às responsabilidades no desenvolvimento de problemas sociais neste contexto. Nesta apreciação, há diferenças significativas em função da idade $\left(X^{2}(1)=4.829, p<.05\right)$ sendo o grupo dos 6-9 anos mais crítico do que os mais velhos (10-13 anos).

Também o espaço público foi alvo de uma apreciação mais negativa, por ser nele que situaram desordens sociais (barulho dia e noite, consumo de álcool na via pública, brigas, conflitos, insultos, ameaças, lutas) e físicas (lixo, graffiti, iluminação pública e mobiliário urbano destruídos, carros abandonados), comuns a todos os bairros. A apreciação negativa do comércio/serviços associa-se à escassez 
de lojas e, sobretudo, à perceção de que os cafés existentes estão na origem de larga parte das desordens, vários em ruas sem saída.

\section{Figura 1}

Valoração posisitva/negativa das crianças sobre os bairros

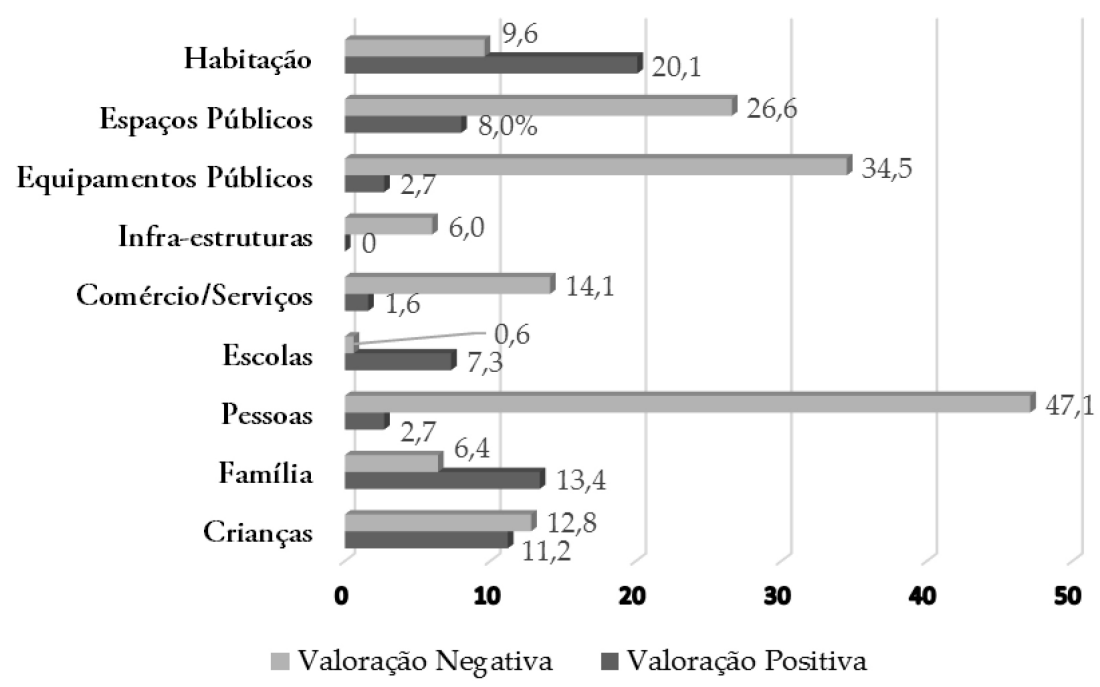

Fonte: Elaboração própria a partir da pesquisa.

As crianças parecem ter uma noção clara sobre os papéis sociais atribuídos aos adultos, referenciado depreciativamente a existência de uma parte que se afasta do que consideram ser o modelo de referência adequado para a manutenção da coesão social e, nos desenhos, vê-se questionada a densidade e natureza dos laços sociais e redes de vizinhança, especialmente entre diferentes origens étnicas. A fragmentação e a heterogeneidade das dinâmicas culturais em presença potenciam uma ideia de clivagem e conflitos duradouros que marcam a vida das crianças. (GUSMÃO, 2004) Não basta a coexistência interétnica num determinado espaço para assegurar trocas gratificantes e positivas entre os indivíduos; é preciso a mobilização para a interação (MACHADO, 2001) como sugeriu uma menina (F17, 9 anos, Bairro Branco): "quero dizer que gostava muito que os bairros fossem melhorados, não é que eles tenham só coisas más, mas é que as pessoas têm de ficar...de ser assim mais amigas umas das outras, mesmo sendo pretos, brancos, ciganos." 
$\mathrm{Na}$ literatura científica, os termos raça, grupo étnico ou etnicidade são objeto de acesa controvérsia e a sua problematização está longe de se revelar consensual. (ABOUD; DOYLE, 1996; MACHADO, 2001; REBELO, 2006; CABECINHAS, 2008) Sabe-se que cada indivíduo não tem uma identidade fixa, mas antes múltiplas identidades em função de diferentes variáveis (idade, gênero, etnia, entre outras), o que pode levar a partilhe uma posição comum com outros indivíduos num determinado assunto e deles divirja noutros. (ACKROYD; PILKINGTON, 1999) No presente, as relaçóes entre grupos culturais revelam-se muitas vezes antagônicas e a constatação da existência do outro suscita o questionamento sobre identidade, alteridade e poder, tendo como pano de fundo a complexificação da vida social (TOMÁS, 2012) e, de modo particular nesta pesquisa, a segregação residencial do contexto em estudo.

\section{"Aqui só há pobres!”}

A pobreza é um fenômeno plural, diverso, que contempla diferentes realidades. (BASTOS, 2013) A dimensão subjetiva da segregação residencial evidencia-se nas formas como as crianças percecionam os efeitos da concentração espacial da pobreza nos bairros.

Falar sobre a pobreza concentrada num território é falar dos múltiplos riscos que representa, dos seus efeitos como resultado de políticas habitacionais de segregação residencial de populaçóes pobres (KOSLINSKI; ALVES; 2012), como as que estiveram na origem destes bairros. As crianças podem estar claramente identificadas aos territórios onde residem, aceitando e incorporando a sua condição social desfavorecida, representando-os como espaços de homogeneidade social que potencialmente excluem-nas da participação na vida social próxima, da cidade e do país (Figura 2).

O bairro surge como uma formação sócio espacial específica e diferenciada, resultante de processos e mecanismos sociais que assentam em lógicas que são simultaneamente de segregação residencial e de agregação de certos grupos sociais num território limitado. São lógicas que decorrem de dinâmicas de massificação, pois concretizam-se no âmbito de políticas públicas através das quais o Estado português tenta debelar a carência de habitação que afeta parte da população no país. Decorrem de dinâmicas de seleção e exclusão que se refletem em diversos patamares no interior destes territórios segregados, uma vez que neles há vários graus de exclusão e de pobreza e modos diferenciados de percecionar e viver estes problemas sociais. 


\section{Figura 2}

$\mathrm{O}$ meu bairro

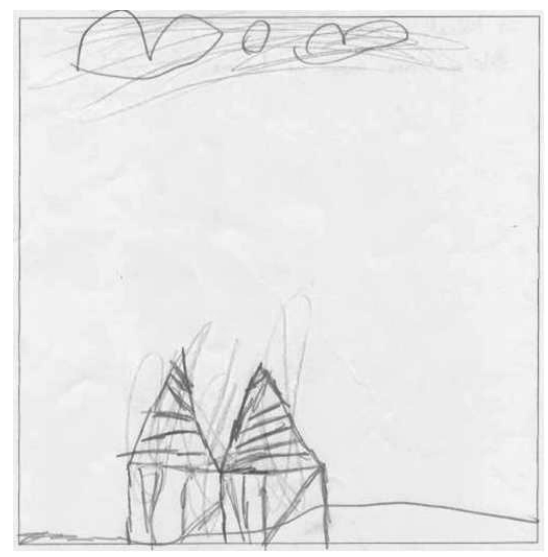

"Está um dia mau no bairro!... O que faz falta no meu bairro é casas e mais casas para as pessoas e um parque. Aqui o que há mais é pessoas pobres, só há pobres, pessoas pobres, só pobres..." (meninoM08, 8 anos, Bairro Amarelo)

\section{Figura 3}

O meu bairro

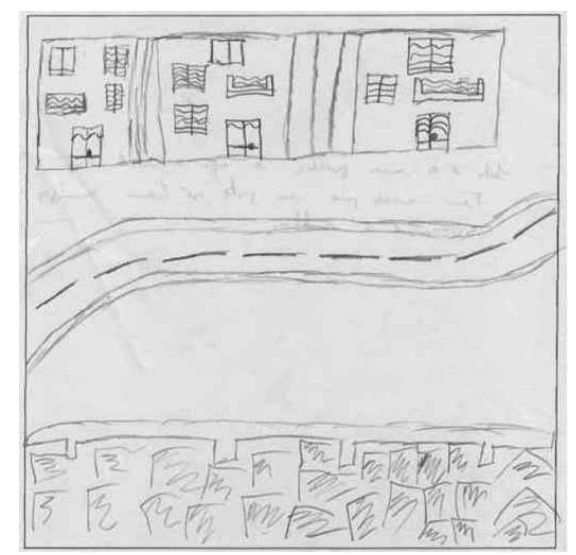

"É seco... o bairro é seco! Então... não tem shopping, não tem lojas como lá fora... não gosto sem isto! O bairro... se for lá ao fundo vejo tudo, ali do fundo dou a volta e dá para ver aqui tudo, é sempre a voltar ao mesmo sitio [...] Faz falta parques, mais um campo de futebol para ir jogar." (meninoM02, 10 anos, Bairro Cinzento)

A ideia do fechamento do bairro em si, em função da organização territorial, agravada pela ausência de equipamentos, é notória nesta descrição 
(Figura 3). Observou-se que os seis bairros tendem a não beneficiar de maior proximidade e trocas de sentido positivo com outras zonas residenciais socialmente diferenciadas, onde as expectativas de controlo social das crianças são mais elevadas, acentuando-se desigualdades de acesso a recursos e serviços a nível espacial (MORENOFF; SAMPSON; RAUDENBUSH, 2001) (Figura 3). A apreciação negativa das crianças sobre os equipamentos públicos associa-se fundamentalmente à ausência de recursos básicos que existem noutros locais, sendo reclamada por $30,2 \%$ das crianças participantes a construção de parques infantis. Reforça-se, assim, a ideia de como a segregação residencial se reflete no reforço de desigualdades sociais. Registaram-se diferenças significativas em termos de idade $\left(X^{2}(1)=5,533, p<.05\right)$ : o grupo nos $10-13$ anos queixou-se mais do que o dos 6-9 anos, o que pode sugerir diferentes formas de ocupação destes equipamentos.

A imposição do realojamento trouxe a passagem das populaçóes para formas de organização social, onde a vida quotidiana se estrutura num plano de verticalidade consubstanciado nos prédios onde residem, em espaços limitados sujeitos a regulamentaçáo municipal, em detrimento do plano de horizontalidade vivido nas anteriores casas, maioritariamente em barracas, onde se tornava possível uma diferente, mais extensa e livre, ainda que ilegal, apropriação do espaço.

"Onde é que fica o Governo? Qual é o bairro onde está o Governo, qual é o bairro? (meninoM13, 12 anos, Bairro Verde) é a pergunta desta criança cuja visão do mundo se centra nos limites do território onde reside. Tudo gira em volta do bairro, que agora é de realojamento mas antes foi de construção ilegal, de barracas, tipo favela. Mas também o olhar do exterior fecha o bairro num território específico, estigmatizado, potencialmente perigoso e ameaçador para quem se encontra fora dele. (WACQUANT, 2007) Estes processos de realojamento que visaram, em primeiro lugar, a melhoria das condiçóes de vida estão na base do estabelecimento de áreas residenciais que, de comum, têm o fato de abranger grupos que já eram objeto de exclusão social, situação que parece manter-se pela segregação residencial que afeta os novos bairros.

\section{"Nós e os outros"}

A compreensão sobre o território e as dinâmicas espaciais é essencial no entendimento dos fenômenos de discriminação. Deste modo, é relevante que as crianças tenham retratado processos de segregação de famílias no interior dos bairros, algumas realojadas por ruas em função da origem étnica, fator sentido como um sério obstáculo a uma melhoria da qualidade de vida (Figura 4).

Quando se fala de bairros de realojamento, a imagem que prevalece na opinião pública portuguesa é a de espaços homogêneos. Os territórios não se limi- 
tam à sua configuração física exterior, e mais significativas podem ser as fronteiras percecionadas e vividas no seu seio, em divisões por micro territórios associados a hierarquias étnicas e grupos sociais específicos. A generalização de expressóes como "a rua dos ciganos", para citar o exemplo mais mencionado pelas crianças, é algo que contribui, e simultaneamente (re)constrói, um permanente mal-estar social, reforçando fenômenos de estigmatização que acentuam o fechamento destes territórios num encapsulamento de natureza étnica e social. (MENEZES; ALMEIDA, 2006)

A aparente nostalgia e desejo de retorno a um passado em que se terá vivido maior privação socioeconômica reflete os fenômenos de exclusóes e inclusôes precárias que Young (1999) aponta na caracterização da sociedade "exclusiva”. Trata-se de situações em que ganha corpo a (re)construção da noção de comunidade à luz da transformaçãa dos processos de uso e apropriação do espaço, em especial do espaço público.

\section{Figura 4}

\section{O meu bairro}

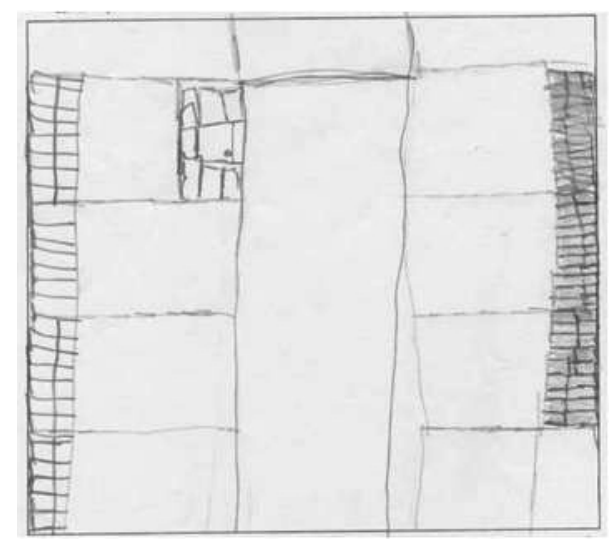

"É a minha rua, a rua dos ciganos e a porta da entrada do meu prédio. Não faço mais nada porque eu náo gosto nada de morar aqui, nada mesmo, gostava era de voltar para a minha antiga casa em (...), era barraca mas era muita melhor a minha vida lá, tinha os meus amigos e aqui não gosto de nada aqui. A minha vida estragou-se!" (meninoM15, 13 anos, Bairro Azul)

A forma como as crianças dispóem e mencionam o uso do espaço de um lado o nós, no lado oposto, os outros -, numa representação que traduz um campo de batalha, não pode ser desvalorizada na análise da sua socialização (Figura 5). 


\section{Figura 5}

O meu bairro

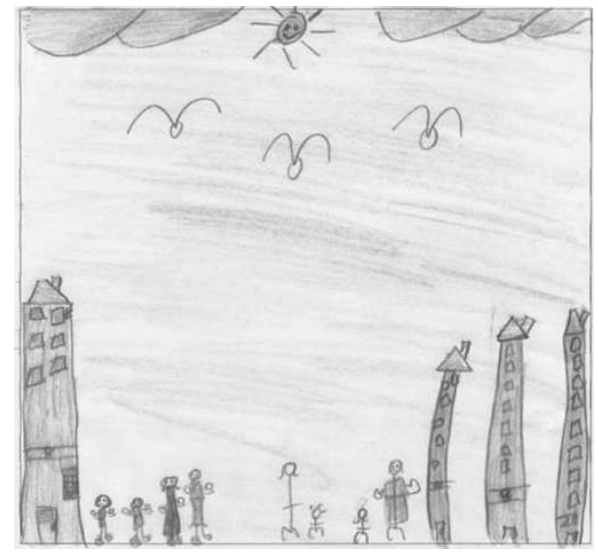

"É o desenho da minha rua e do lado dos prédios dos ciganos e do outro eu e as minhas amigas. O que eu gosto menos no meu bairro é dos ciganos e se eu pudesse eu mudava eles de bairro porque eles sujam a rua, são malcriados e barulhentos." (meninaF13, 9 anos, Bairro Branco)

\section{Figura 6}

\section{O meu bairro}

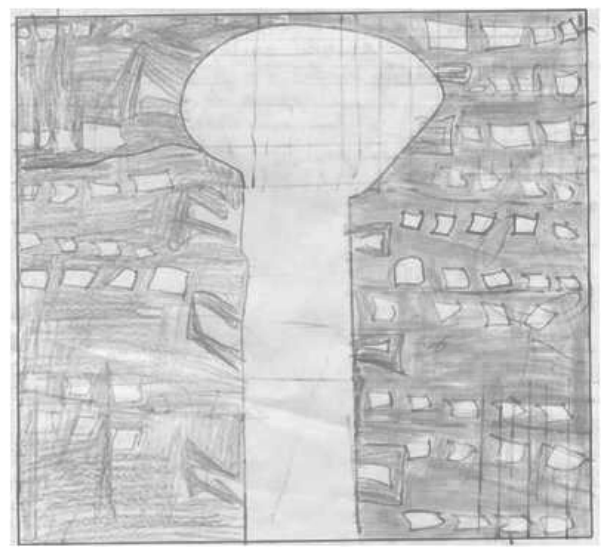

"A rua tem um molho de prédios, tem a rotunda que tem lá o espaço para pôr os carros. Tem uns prédios amarelos [lado direito do desenho] e outros cor-de-rosa [lado esquerdo] e os prédios não podem ser todos iguais. (...) Nós, os ciganos, vivemos quase todos nos prédios amarelos.

No meu prédio só vivem dois senhores [brancos] que não são ciganos e nos outros prédios amarelos vivem muitos ciganos, uns senhores, e pretos é que é menos, é sempre mais ciganos." (meninoM16, 8 anos, Bairro Azul) 
A tomada de consciência em relação a detalhes arquitetónicos, como o da cor diferenciada do prédio (Figura 6), torna visível como aspetos do edificado podem constituir fonte de conflito, não só entre os que aí moram mas também entre parte destes e o município. A concentração de famílias ciganas numa banda de prédios de cor diferente das restantes de um dos bairros é descrita como uma forma de racismo levada a cabo pelo município, surgindo os ciganos como uma das categorias mais associada à degradação do espaço e equipamentos públicos, até em desenhos e discursos de crianças desta etnia.

A divisão social do espaço assente em critérios de distribuição étnica produz relaçóes de poder que se institucionalizam entre os residentes num clima de permanente oposição e de procura de domínio territorial, que as crianças apropriam e reconstroem nas culturas de pares. Numa linha similar à registrada por Cabecinhas e Amâncio (2003) em pesquisa envolvendo jovens portugueses, nesta pesquisa apurou-se que apesar de as tipologias raciais terem sido abolidas há muito nas sociedades ocidentais, as mesmas continuam a prevalecer no discurso e açóes da maioria dos residentes, independentemente de gênero, idade ou origem. Os termos "preto", "branco", "cigano", "negro", "tuga", "branquelas"; "mulato", "pula", "black", "castanho", "senhores", "português" têm uma forte presença nas palavras das crianças, constituindo estas categorizações uma marca significativa da discriminação nas culturas de infância aqui produzidas. Tende a prevalecer uma noção do outro que se vê como diferente, em posição de subalternidade que conduz à sua rejeição e, diversamente do sugerido por Aboud (1988), a idade não é uma variável diferenciadora destas atitudes. ${ }^{5}$

O que é mau aqui é os pretos, os pretos, não gosto nada dos pretos, são muito [sic]... assaltam muito, partem tudo, náo gosto de ter tantos pretos aqui, náo gosto. (meninoM02, 9 anos, Bairro Azul)

Estou farta dos ciganos e dos pretos, fazem barulho a noite toda, póem música alto, roubam e tudo... (meninaF11, 7 anos, Bairro Verde)

Eu tirava os brancos do bairro porque eles só fazem muito barulho, não ligam à gente e porque estão sempre a roubar ao meu avô, levam os ferros. Os ciganos também quando lá vão é só para roubar, são uns porcos e bandidos. [...] Eu tirava os brancos e os mulatos, punha só pretos, só pretos que temos mais força. (meninoM11, 8 anos, Bairro Rosa)

Não gosto dos ciganos, detesto! Queria o bairro todo de pretos, poucos brancos que dáo fixe com os pretos mesmo. Os ciganos dão mal, os brancos picam os pretos, poucos são bons. Os ciganos nem um, têm a mania! (meninoM13, 11 anos, Bairro Verde) 
Os excertos apresentados não se reportam a situações isoladas na análise, suscitando a ideia da existência de hierarquias e estatutos que cada grupo tende a construir. Estes choques revelam-se de forma intensa na necessidade de afirmaçáo pessoal e social (CASTRO et al., 2006), assente numa linguagem segregadora e racista, mas que nada mais será do que o espelho de como experiências de discriminação marcam muitas crianças. A gênese do preconceito traduzida nestes discursos - na qualidade de "uma predisposição organizada para responder de forma desfavorável a determinados indivíduos" (MACHADO et al., 2007, p. 119) - surge em idades baixas. Para alguns autores, é produto do insuficiente amadurecimento das estruturas afetivo cognitivas que se traduz numa fase de egocentrismo (ABOUD, 1988), enquanto para outros é necessário questionar o papel da aprendizagem e interiorização de normas sociais perante os modelos sociais presentes num contexto. (FRANÇA; MONTEIRO, 2004)

Não se encontrou nesta pesquisa sustentação para a defesa da ideia que o contato entre diferentes grupos étnicos possibilita mais facilmente que uns e outros identifiquem as semelhanças, promovendo uma abertura à compreensão e respeito mútuos. (MACHADO et al., 2007) Este contato permanente que se vê desenvolvido nestes territórios, sobretudo pelas crianças que são obrigadas a partilhar a frequência nas mesmas escolas, parece alimentar uma profunda desconfiança reveladora da fragilidade das relaçóes e laços sociais. Se até certo ponto esta atitude pode encontrar razão de ser no passado cultural dos grupos maioritariamente em presença - origem africana versus cigana -, a dimensão visível e continuada do problema suscita a possível associação a outras desvantagens sociais que não se conseguem atenuar dada a sua elevada concentração espacial.

\section{Considerações finais}

Numa sociedade que faz da segregação e da discriminação um modo de gestão das dinâmicas sociais, assente num individualismo que pode atingir níveis exacerbados tanto na esfera mais próxima de cada comunidade como, a nível mais alargado, no mercado de trabalho e no sistema produtivo (YOUNG, 1999), ter em consideração o olhar das crianças sobre os problemas sociais que as afetam abre horizontes que remetem para a sua compreensão como entidade participativa na construção da realidade e da mudança social.

$\mathrm{Na}$ complexificação das relaçóes sociais emerge, a partir do olhar das crianças sobre o contexto em estudo, um processo de etnização dos laços e redes sociais que tendem a fechar-se em torno da sua origem étnica, não sendo específicas de um grupo em concreto, mas antes se alargando a todos os que ali vivem. Ainda que, por limitaçóes legais, não tenha sido possível usar a variável etnia no aprofundamento da análise, é notório como a mesma é fulcral nas dinâmicas so- 
ciais que marcam a socialização destas crianças, como patente nos seus discursos. Esta limitação metodológica deve ser questionada pelos efeitos perversos que pode acarretar e entre os quais se inclui o reforço de estereótipos e preconceitos.

A discriminação étnica retratada pelas crianças tende a ser feita em relação a todos os grupos, de modo abrangente e multidirecional. Esta situação assume especial relevância em determinadas situaçóes e a estratificação social dentro de um mesmo grupo étnico é similarmente factor de discriminação. O posicionamento espacial no interior dos bairros acentua fenômenos de estigmatização e discriminação e concretiza-se à luz de normas e tradiçóes culturais que estruturam as perceções das crianças.

Muitas crianças manifestam uma forte e positiva identificação com o grupo étnico de origem; mas quando exacerbada, esta adesão acarreta uma permanente desconfiança e hostilidade em relação aos outros grupos, facilmente surgindo os conflitos no acesso a posiçóes e estatutos específicos. A etnização dos laços e redes sociais nos bairros serve para a construção das competências das crianças, estruturando no presente as relaçóes entre pares e com adultos. A oralidade assume uma especial influência, sendo a partir dela que muitas situaçóes de conflito são concretizadas.

As formas de discriminação social e étnica identificadas têm de ser pensadas a partir da sua articulação com as lógicas de exclusão e de segregação em relação com os espaços onde tomam corpo. (WACQUANT, 2007) Se a segregação é uma qualidade intrínseca e percecionada pelas crianças no que diz respeito a estes bairros, ela reenvia o olhar para as formas como os residentes vivem na relação com o exterior, numa linha, por vezes, marcada por sentimentos de dependência, de frustração e até de revolta. A separação espacial dos bairros relativamente a outras zonas residenciais é reforçada pela degradação dos espaços e equipamentos públicos e a segregação residencial acaba por ser representada como uma forma de violência; por um lado, física, pelas limitaçóes que impóe, por outro simbólica, pelos efeitos que acarreta nas relaçóes sociais. E outras formas de violência podem nascer nos interstícios das aspiraçôes e necessidades básicas, da experiência quotidiana da rejeição e relegação a que muitos dos residentes se veem sujeitos; no fundo uma forma de violência inerte que acentua um sentimento de fatalidade social que as próprias crianças interiorizam. (WACQUANT, 2007; MOIGNARD, 2008) 


\section{Notas}

1. Para preservar a sua identidade, os nomes das crianças foram substituídos por códigos alfanuméricos e, no caso dos bairros, por cores: Amarelo, Rosa, Azul, Verde, Cinzento e Branco.

2. Correspondente aos quatro primeiros anos de escolaridade do ensino fundamental no Brasil.

3. Atualmente, este programa abrange 137 agrupamentos de escolas no país. Mais informação disponível em http://www.dgidc.min-edu.pt/teip/

4. Lei no 67/98, de 26 de Outubro, Lei da Proteção de Dados Pessoais (transpóe para a ordem jurídica portuguesa a Diretiva no 95/46/CE, do Parlamento Europeu e do Conselho, de 24 de Outubro de 1995, relativa à proteçấo das pessoas singulares no que diz respeito ao tratamento dos dados pessoais e à livre circulação desses dados).

5. Ideia também identificada por França e Monteiro (2004) em estudos com crianças brasileiras entre os 5 e os 10 anos de diferentes origens sociais.

\section{Referências}

ABOUD, F.; DOYLE, A. Does talk of race foster prejudice or tolerance in children? $\mathrm{Ca}$ nadian Journal of Behavioural Science, Ontario, v.28, n. 3, p. 161-170, 1996.

ABOUD, F. Children and Prejudice. New York: Blackwell, 1988.

ACKROYD, J.; PILKINGTON, A. Childhood, and the construction of ethnic identities in a global age. A dramatic encounter. Childhood, Trondheim, v. 6, n. 4, p. 443-454, 1999.

BASTOS, A. Pobreza infantil - um problema preocupante. Rediteia - Revista de Política Social, Porto, n. 46, p. 9-15, 2013.

BENBENISTHY, R.; ASTOR, R. School violence in context: culture, neighbourhood, family, school and gender. New York: University Press, 2005.

CABECINHAS, R. Racismo e xenofobia: a actualidade de uma velha questão. Comunicación e Cidadanía, Galicia, n², p. 163-182, 2008. [Observatorio Galego dos Medios]. Disponível em http://hdl.handle.net/1822/9639. Acesso em 22 jun. 2010.

CABECINHAS, R.; AMÂNCIO, L. Naturalização da diferença: representações sobre raça e grupo étnico. In: JORNADA INTERNACIONAL SOBRE REPRESENTAÇÕES SOCIAIS, 3., 2003. Rio de Janeiro, 2003. Anais... Rio de Janeiro: Faperj, 2003. Disponível em http://repositorium.sdum.uminho.pt/bitstream/1822/1598/1/rcabecinhas lamancio JIRS 2003.pdf. Acesso em: 2 dez. 2013.

CASTRO, L. et al. A construção da diferença: jovens na cidade e as suas relaçôes com o outro. Psicologia em Estudo, Maringá, v. 11, n. 2, p. 437-447, 2006.

CHRISTENSEN, P.; O'BRIEN (Orgs.). Children in the City. Home, Neighbourhood and Community. Oxon: Routledge, 2003. 
CORSARO, W. The sociology of childhood. Thousand-Oaks-California: Pine Forge Press, 1997.

FRANÇA, D.; MONTEIRO, M. A expressão das formas indirectas de racismo na infância. Análise Psicológica, Lisboa, v. 4, n. XXII, p. 705-720, 2004.

GUSMÃO, N. Os filhos da África em Portugal. Antropologia, multiculturalidade e educação. Lisboa: Instituto de Ciências Sociais da Universidade de Lisboa, 2004.

KOSLINSKI, M.; ALVES, F. Novos olhares para as desigualdades de oportunidades educacionais: a segregação residencial e a relação favela-asfalto no contexto carioca. Educação \& Sociedade, Campinas, v. 33, n.120, set. 2012. Disponível em http://www.scielo. br/scielo.php?script $=$ sci arttext \&pid=S0101-73302012000300009\&lng=pt\&nrm=iso. Acesso em: 08 nov. 2013.

MACHADO, F. Contextos e percepçóes de racismo no quotidiano. Sociologia, Problemas e Práticas, Lisboa, v. 36, p. 53 -80, 2001.

MACHADO, P. et al. Metrópoles Seguras. Bases para uma Intervenção Multissectorial nas Áreas Metropolitanas de Lisboa e do Porto. Volume III. Lisboa: LNEC, 2007 (documento não publicado).

MENEZES, M.; ALMEIDA, A. Direito à cidade. Reflexão em torno da incidência do termo mistura social nas políticas habitacionais e urbanas portuguesas. Lisboa: LNEC, 2006.

MOIGNARD, B. L'école et la rue: fabriques de délinquance. Recherches comparatives en France et au Brésil. Paris: PUF, 2008.

MORENOFF, J.; SAMPSON, R.; RAUDENBUSH, S. Neighborhood inequality, collective efficacy, and the spatial dynamics of urban violence. Criminology, Pennsylvania, v. 39, n. 3, p. 517-558, 2001.

OLIVEIRA, C. et al. Violência e Cidade: existiria uma geografia do crime? O Público e o Privado, Ceará, n4, p. 87-101, 2004.

REBELO, M. Estudos em branco e negro: modelos de redução do preconceito inter-étnico na infância. Lisboa: LNEC, 2006.

SASSEN, S. The global city: New York, London, Tokyo. New Jersey: Princeton University Press, 2001.

SARMENTO, M. Conhecer a infância: os desenhos das crianças como produçóes simbólicas. In: FILHO, A.; PRADO, P. (Orgs.). Das pesquisas com crianças à complexidade da infância. Campinas: Autores Associados, 2011, p. 27-60.

SEATON, E.; TAYLOR, R. Exploring processes in urban, low-income African American families. Journal of Family Issues, Florida, v. 24, n. 5, p. 627-644, 2003.

TOMÁS, C. A Diferença que a cor faz: infância, educação e racismo. In: FETZENER, A. (Org.). Como romper com as maneiras tradicionais de ensinar? Reflexóes didático-metodológicas. Rio de Janeiro: WAK Editora, 2012, p.81-104. 
Segregação residencial e discriminação na área metropolitana de Lisboa

WACQUANT, L. Parias urbains: ghetto, banlieues, État. Paris: Éditions La Découverte, 2007.

YOUNG, J The exclusive society. Social exclusion, crime and difference in late modernity. London: Sage Publications, 1999.

Recebido em 14 de maio de 2014.

Aprovado em 24 de outubro de 2014. 